\title{
Effects of disease activity on lipoprotein levels in patients with early arthritis: can oxidized LDL cholesterol explain the lipid paradox theory?
}

Ana M. Fernández-Ortiz , Ana M. Ortiz², Silvia Pérez³, Esther Toledano ${ }^{4}$, Lydia Abásolo ${ }^{4}$, Miguel A. González-Gay ${ }^{5}$, Santos Castañeda ${ }^{2,6}$ and Isidoro González-Álvaro ${ }^{2^{*}}$ (i)

\begin{abstract}
Background: An increased risk of cardiovascular (CV) complications has been described in patients with rheumatoid arthritis (RA). It is the result of the combined effect of classic CV risk factors and others that are specific to the disease.

Methods: We assessed data from 448 early arthritis (EA) patients: 79\% women, age (median [p25-p75]) at onset: 55 [44-67] years and disease duration at study entry 5 [3-8] months; and 72\% fulfilled the 1987 RA criteria at 2 years of follow-up. Rheumatoid factor was positive in $54 \%$ of patients and anti-citrullinated peptide antibodies in $50 \%$. The follow-up of patients ranged from 2 to 5 years with more than 1400 visits with lipoprotein measurements available (mean 2.5 visits/patient). Demographic- and disease-related variables were systematically recorded. Total cholesterol (TC), high-density lipoprotein (HDL-C), and low-density lipoprotein (LDL-C) levels were obtained from routine laboratory tests. Oxidized-LDL (oxLDL-C) levels were assessed using a commercial ELISA kit. We fitted populationaveraged models nested by patient and visit to determine the effect of independent variables on serum levels of $T C$, its fractions, and oxLDL-C.

Results: After adjustment for several confounders, high-disease activity was significantly associated with decreased TC, HDL-C, and LDL-C levels and increased oxLDL-C levels. Standardized coefficients showed that the effect of disease activity was greater on oxLDL-C and HDL-C. Interestingly, we observed that those patients with lower levels of LDL-C showed higher oxLDL-C/LDL-C ratios.

Conclusions: High-disease activity in EA patients results in changes in the HDL-C and oxLDL-C levels, which in turn may contribute to the increased risk of $\mathrm{CV}$ disease observed in these patients.
\end{abstract}

Keywords: Rheumatoid arthritis, Cholesterol, oxLDL-C

\section{Background}

There is a great body of evidence supporting that patients with rheumatoid arthritis (RA) display a higher

\footnotetext{
* Correspondence: isidoro.ga@ser.es

${ }^{2}$ Rheumatology Division, Hospital Universitario La Princesa, IIS-IP, Diego de León 62, 28006 Madrid, Spain

Full list of author information is available at the end of the article
}

risk of cardiovascular events (CVE) than the general population [1-5]. In addition, several studies have shown that scores for predicting cardiovascular (CV) risk in the general population based on traditional $\mathrm{CV}$ risk factors (smoking, hypertension, obesity, diabetes, and dyslipidemia) underestimate the CV risk in patients with RA [610]. This additional risk for CVE has been studied in

C C The Author(s). 2020 Open Access This article is licensed under a Creative Commons Attribution 4.0 International License, which permits use, sharing, adaptation, distribution and reproduction in any medium or format, as long as you give appropriate credit to the original author(s) and the source, provide a link to the Creative Commons licence, and indicate if changes were made. The images or other third party material in this article are included in the article's Creative Commons licence, unless indicated otherwise in a credit line to the material. If material is not included in the article's Creative Commons licence and your intended use is not permitted by statutory regulation or exceeds the permitted use, you will need to obtain permission directly from the copyright holder. To view a copy of this licence, visit http://creativecommons.org/licenses/by/4.0/. The Creative Commons Public Domain Dedication waiver (http://creativecommons.org/publicdomain/zero/1.0/) applies to the data made available in this article, unless otherwise stated in a credit line to the data. 
terms of specific genetic background $[3,11]$ and in relation with the effect of disease activity on lipid profile in these patients [12-19].

There is an increased CV risk in the general population associated with an increase in total cholesterol (TC), mainly low-density lipoprotein cholesterol (LDLC), and a decrease in high-density lipoprotein cholesterol (HDL-C) levels, and, as a consequence, an increase in the atherogenic index [20]. However, in patients with active RA and other inflammatory disorders a "paradoxical phenomenon" occurs with a decrease in TC and LDL-C associated with an increase in $\mathrm{CV}$ risk $[5,21,22]$. Furthermore, recently, it has been observed that those patients with very low LDL-C show a stronger association with subclinical coronary atherosclerosis, similar to that of patients with the highest levels of LDL-C, which has been termed "the lipid paradox theory" [23]. The relationship between changes in the lipid metabolism and RA disease activity has been analyzed in previous studies with controversial results [12-19]. Several concerns related with previous studies may explain these controversial results. Lipid profile in RA has been studied both in observational cross-sectional studies of long-standing RA and in randomized clinical trials in patients with early arthritis (EA). Moreover, many of these studies included a low number of patients and different outcomes were measured in each work [12-19, 24-26].

An issue of potential interest regarding lipid profile disturbances that appear over time in patients with RA is whether these alterations are observed at the early stages of the disease. To address this question, we analyzed how disease activity affects the lipid profile in a population of patients with early arthritis without any treatment at the baseline visit, who were followed-up for up to 5 years in five protocolized visits.

\section{Patients and methods Design and patients}

Retrospective analysis of data collected in the PEARL (Princesa Early Arthritis Register Longitudinal) study in order to determine the effect of disease activity on the lipid profile of patients with early arthritis.

PEARL study includes incident cases of patients with one or more swollen joints for less than a year referred to our EA Clinic. Patients with gout, septic or viral arthritis, osteoarthritis, spondyloarthritis, or connective tissue diseases diagnosed during the follow-up period were excluded from this analysis. Only those patients fulfilling the 1987 ACR criteria for RA classification [27] and those considered undifferentiated arthritis (UA) [28] after 24 months of follow-up were included in this study. The register includes 5 structured visits (baseline, 6, 12, 24 , and 60 months) in which socio-demographic, clinical, laboratory, therapeutic, and radiological data as well as biological samples are systematically collected in parallel with routine analysis after, at least, $10 \mathrm{~h}$ of fasting.

It is important to point out that there is no preestablished therapeutic protocol in the PEARL study, so the decision on when and how to treat the patients during the follow-up relies on the responsible physicians from the rheumatology department (see Supplementary Table 1 for the description of treatments along with the follow-up). Nevertheless, the register specific evaluation visits are performed by only two rheumatologists (AMO, IG-A) in an attempt to achieve more accurate clinical evaluation, especially regarding joint counts. A more detailed description of the PEARL study has been previously published [29]. The register started in 2000 and it is still ongoing. However, for this analysis, we only used the visits included in the database until June 2018.

Disease activity stratification was performed applying cut-offs previously described: DAS28 estimated using either erythrocyte sedimentation rate (ESR) [30] or Creactive protein (CRP) [31], Simplified Disease Activity Index (SDAI) and Clinical Disease Activity Index (CDAI) [32], and Hospital Universitario Princesa Index (HUPI) [33]. Disability was assessed with the Spanish version of the Health Assessment Questionnaire (HAQ) [34].

\section{Lipid profile measurements}

TC levels, HDL-C, LDL-C, very low-density lipoproteins (VLDL-C) fractions, and triglycerides (TG) levels were estimated in routine blood tests at the local biochemistry laboratory of our center. TC, HDL-C, and TG concentrations were determined through the enzymatic method in a Hitachi 911 analyzer (CHOP-PAP, GPO-PAP, and HDL-direct, respectively; Roche Diagnostics). LDL-C was estimated through the Friedewald formula [35, 36]: $\mathrm{LDL}=\mathrm{TC}-\mathrm{HDL}-0.2 \times \mathrm{TG}$.

Although it was established per protocol to measure the total lipid profile in all visits, due to the fact that some patients missed some visits or to the occasional decision of the biochemistry laboratory to skip measuring cholesterol fractions when TC was below $200 \mathrm{mg} / \mathrm{dl}$, there were missing data for some of the variables. Therefore, the data from blood tests available for analyses were TC from 1416 visits, HDL-C from 977 visits, LDLC from 929 visits, VLDL-C from 717 visits, and TG from 848 visits.

\section{Oxidized-LDL evaluation}

Since our center does not routinely measure oxidizedLDL-C (oxLDL-C) levels, we determined them in frozen serum samples from our register through a commercial ELISA kit (Mercodia AB, Uppsala, Sweden) following the manufacturer's instructions for use. To evaluate the effect of frozen storage time on oxLDL-C measurements, we analyzed a subpopulation of 104 samples with a 
range of storage from 6 to 40 months evenly distributed throughout our register. As it is shown in Supplementary Figure 1, for periods of frozen storage longer than 12 months, the capability to measure oxLDL-C levels was severely impaired. Therefore, we decided to perform the current study exclusively with samples that were frozen for less than 12 months. This approach allowed us to obtain data about oxLDL-C serum levels from 270 visits from a subpopulation of 167 patients (1.5 visits per patient). The intra- and inter-assay variability were calculated by repeating four samples (two with high value and two with a low value) in six wells of four independent ELISA plates. According to our measurements, intra-assay and inter-assay variability coefficients were $9.5 \%$ and $22.3 \%$, respectively.

\section{Statistical analysis}

Normally distributed quantitative variables were represented as the mean ( \pm standard deviation: SD), while non-normally distributed variables were represented as the median and interquartile range (IQR). Qualitative variables were described using a calculation of the proportions. Variables with a normal distribution were analyzed by the $t$ test or ANOVA, while the Mann-Whitney or Kruskal-Wallis tests were used for variables with a non-normal distribution. A $\chi^{2}$ or Fisher's exact test was used to compare categorical variables.

After bivariate analysis to identify independent factors that influenced TC, HDL-C, LDL-C, oxLDL-C, VLDL-C, and TG levels during the follow-up, we fitted six population-averaged models by generalized linear models nested by the patient and visit using the xtgee command of Stata 12.1 for Windows (StataCorp LP, College Station, Texas, USA). Since oxLDL-C values did not follow a Gaussian distribution, this variable was normalized by calculating the square root of its values. In this case, the sqrt_oxLDL-C variable was used as a dependent variable. The remaining models were fitted with the raw data since TC, HDL-C, LDL-C, VLDL-C, and TG levels approximately followed Gaussian distributions. The population-averaged generalized estimating equations were first modeled by adding all variables with a $p$ value $<0.15$ in the bivariate analysis. The final models were constructed using quasi-likelihood estimation based on the independence model information criterion [37] and Wald tests, removing all variables with $p>0.15$. The variable time of frozen storage was always included in the multivariate analysis of oxLDL-C levels. Since six different multivariate analyses were fitted, to adjust for multiple comparisons, we applied Bonferroni correction and the statistical significance was set at < 0.01 .

We performed sensitivity analyses for all dependent variables repeating the statistical models only with the visits in which patients were not taking statins. These sensitivity analyses yielded no relevant differences with the models that included the whole population (Supplementary Table 2).

In addition, to compare which variables had a proportionally higher influence on the lipoprotein profile, we estimated standardized coefficients by repeating the multivariate analysis with new standardized variables generated with the egen command of Stata with the option $s t d$, which produces variables with mean 0 and standard deviation 1 .

To determine which component of disease activity indexes was responsible for most of the effect on lipids, in the models with standardized variables, we replace the variable disease activity by the individual standardized components, namely CRP, swollen and tender joint counts, and global disease assessment by the patient.

\section{Results}

\section{Description of the population}

The baseline characteristics of patients are shown in Table 1 . Briefly, the study sample comprised 448 patients; $79 \%$ of them were women and 324 (72\%) fulfilled 1987 ACR criteria for RA classification, while 124 (28\%) were classified as UA. The median age at baseline was 55 years (interquartile range [IQR] 44-67) and the median disease duration 5 months (IQR: $3-8$ ). Baseline disease activity on average was moderate with all the 5 indexes used in the study.

The HAQ showed mild/moderate disability. Almost half of the population suffered from the seropositive disease [(rheumatoid factor (RF) or anti-citrullinated peptide antibodies (ACPA)], and 21\% were active smokers and the average body mass index (BMI) of patients indicated a slight overweight. Less than $11 \%$ of patients were using statins at baseline and information on the use of these drugs was collected at each visit.

\section{Differences between patients with or without oxLDL-C measurement}

As shown in Table 1, oxLDL-C was assessed in 167 of the 448 patients. This subgroup of patients had longer disease duration at baseline and a non-significantly increased disease severity. However, other features were similar in both groups. (Table 1). Therefore, patients in which oxLDL-C was analyzed constituted a representative cohort of Spanish individuals with EA. In this regard, Supplementary Table 1 shows that patients were mainly treated with methotrexate, antimalarials, and leflunomide without significant differences between both groups. In addition, a non-significant trend to higher percentages of patients treated with tocilizumab, abatacept, or rituximab was observed in patient in which oxLDL-C measurement was not carried out. 
Table 1 Baseline characteristics of patients included in the PEARL study

\begin{tabular}{lllll}
\hline & Total population $(\boldsymbol{N}=\mathbf{4 4 8})$ & oxLDL not studied $(\boldsymbol{N}=\mathbf{2 8 1})$ & oxLDL studied $(\boldsymbol{N}=\mathbf{1 6 7})$ & $\boldsymbol{p}$ \\
\hline Female gender (\%) & $354(79)$ & $224(79.7)$ & $130(77.8)$ & $52[43-65]$ \\
Age (years) & $55[44-67]$ & $58[44-68]$ & $6[4-9]$ & 0.638 \\
Disease duration (months) & $5[3-8]$ & $5[3-8]$ & $4.7[3.5-5.7]$ & 0.08 \\
DAS28 & $4.4[3.3-5.5]$ & $4.1[3.3-5.5]$ & $19.2[10.4-29.5]$ \\
SDAl & $18[9.6-29.2]$ & $17[8.8-29]$ & $8[5-9.5]$ & 0.004 \\
HUPI & $7[4.5-10]$ & $7[4-10]$ & 1 & 0.060 \\
HAQ & 0.875 & 0.875 & {$[0.625-1.625]$} \\
& {$[0.5-1.625]$} & {$[0.375-1.625]$} & 48 & 0.183 \\
RF (\%) & 54 & 57 & 46 & 0.174 \\
ACPA (\%) & 50 & 53 & 30 & 0.059 \\
UA (\%) & 28 & 26 & 24.2 & 0.054 \\
Smoking (\%) & 21.4 & 20 & 9 & 0.175 \\
Statins use (\%) & 10.7 & 12 & $26.3[23.9-29.1]$ \\
BMI p50 [IQR] & $26.1[23.4-29]$ & $25.9[22.9-29]$ & & 0.297 \\
\hline
\end{tabular}

Significance was considered if $p<0.05$. In bold significant $p$ values

Abbreviations: ACPA anti-citrullinated protein antibodies, BMI body mass index, DAS28 Disease Activity Score (28 joints count), HAQ Health Assessment Questionnaire, HUPI Hospital Universitario La Princesa Index, IQR interquartile range, $N$ number, oxLDL oxidized LDL cholesterol, $p p$ value, $P E A R L$ Princesa Early Arthritis Register Longitudinal, RF rheumatoid factor, SDAl Simplified Disease Activity Index, UA undifferentiated arthritis

Table 2 Variables that have an influence on lipid profile of patients with early arthritis

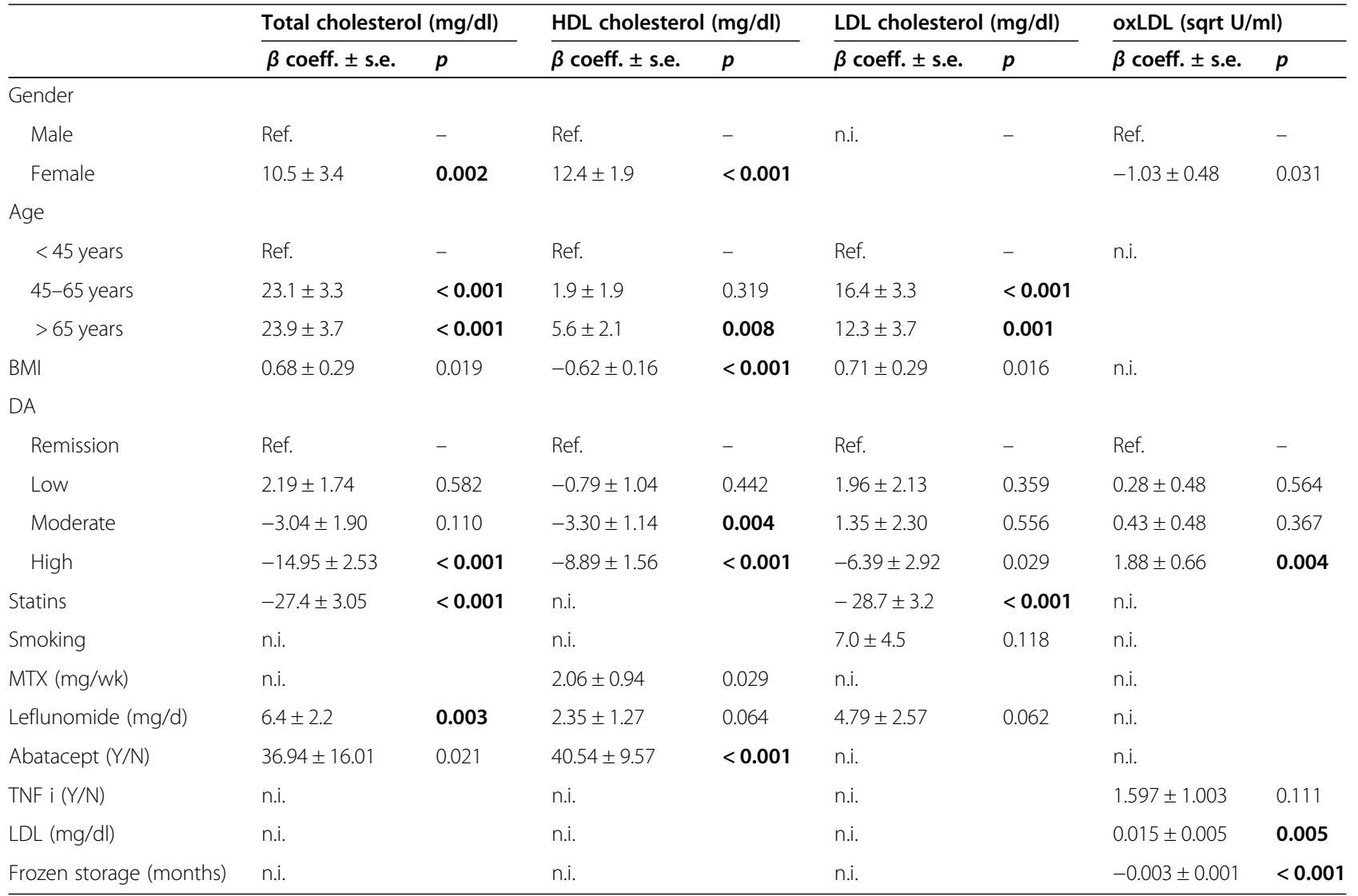

Abbreviations: $\beta$ coeff. beta coefficient, BMI body mass index, DA Disease activity assessed with, HUPI Hospital Universitario La Princesa Index, HDL high-density lipoproteins, $L D L$ low-density lipoproteins, $M T X$ methotrexate, $N$ no, n.i. not included (not relevant to the model), oxLDL oxidized LDL, $p p$ value, Ref. reference variable, s.e. standard error, sqrt square root, n.i. not included (not relevant to the model), TNFi TNF inhibitors, wk week, $Y$ yes. Due to multiple comparisons, statistical significance was considered if $p<0.01$. In bold, significant $p$ values 
Variables associated with TC levels throughout the follow-up of early arthritis patients

As shown in Table 2, TC was significantly higher in female and patients older than 45 years, as well as in those visits in which patients were being treated with leflunomide. In addition, a non-significant trend to higher levels of TC was observed with increasing BMI, as well as in visits in which the patients were being treated with abatacept (Table 2). As expected, TC was significantly lower in those visits in which patients were being treated with statins (Table 2).

After adjustment for these confounders, we observed that only high-disease activity according to HUPI assessment was significantly associated with lower levels of TC (Table 2).

The most relevant variable affecting $\mathrm{TC}$ was age, followed by statins (Fig. 1a). Disease activity had an effect similar to those of gender and BMI (Fig. 1a).

Similar findings were observed when disease activity was assessed with other indexes (Supplementary Tables $3,4,5$, and 6).

\section{Variables associated with HDL-C levels throughout the follow-up}

As described for TC, female patients showed a significant increase of HDL-C levels compared to male patients (Table 2). Using individuals younger than 45 years as a reference, a trend for high HDL-C levels was observed in patients older than 65 years (Table 2). In contrast, HDL-C levels significantly decreased with increasing values of BMI (Table 2). After adjustment for these variables, the multivariate analysis showed that increasing levels of disease activity induced a dosedependent decrease of HDL-C, being statistically significant for moderate and high-disease activity (Table 2). Treatment with methotrexate, leflunomide, and abatacept was also associated with an independent increase of HDL-C levels, which was only statistically significant for abatacept (Table 2).

Regarding the magnitude of the effect on HDL-C levels, disease activity showed an effect size similar to BMI, age, and gender, whereas the relative effect of treatments seemed to be lower (Fig. 1b). Additional information about data related to disease activity assessed with other indexes is shown in Supplementary Tables 3, 4,5 , and 6 .

\section{Variables associated with LDL-C levels throughout the follow-up}

As expected, LDL-C levels were significantly lower in those visits in which the patients were being treated with statins (Table 2). In contrast, LDL-C levels were significantly higher in patients older than 45 years and increased in parallel with increasing BMI (Table 2).
High-disease activity was significantly associated with lower LDL-C levels (Table 2), although compared to other variables that significantly affected LDL-C levels, the effect of disease activity was clearly mild (Fig. 1c). Similar findings were observed when disease activity was assessed with other activity indexes (Supplementary Tables $3,4,5$, and 6 ).

\section{Variables associated with oxidized LDL-C levels}

As mentioned in the "Patients and methods" section, the frozen time of serum samples significantly decreased the capability to detect oxLDL-C (Table 2 and Supplementary Figure 1). In addition, oxLDL-C levels were directly associated with total LDL-C levels (Table 2). Women showed slightly lower oxLDL levels than men, although no statistical significance was reached (Table 2).

After adjustment for these relevant variables, the multivariate analysis showed a significant increase of oxLDL-C levels when disease activity was high (Table 2). This effect was similar to that of LDL-C levels (Fig. 1d).

Additional information about data related to disease activity assessed with other indexes is shown in Supplementary Tables 3, 4, 5, and 6.

On the other hand, it has been recently described that patients with low-circulating LDL-C or very high-LDL-C show a stronger association with subclinical coronary atherosclerosis than patients with normal LDL-C [23]. We were interested in knowing whether this lipid paradox in RA patients could be explained by LDL-C oxidation. Figure 2 shows that the proportion of oxidized LDL-C (oxLDL-C/LDL-C ratio) was significantly higher in visits in which patients showed high-disease activity. Despite this observation, a clear correlation between oxLDL-C and LDL-C levels was only observed in visits in which patients showed low-disease activity (Fig. 3 upper right panel). Interestingly, in visits in which patients had moderate or high-disease activity, patients with low LDL-C showed similar levels of oxLDL-C than those with higher LDL-C (Fig. 3 lower panels). Furthermore, the proportion of oxLDL-C was significantly higher in patients with the lowest level of total LDL-C (Fig. 4).

\section{Variables associated with VLDL-C and TG levels}

The main variable associated with these lipid fractions was BMI. Neither relevant nor significant effect of disease activity was observed in the serum levels of these two parameters (Fig. 1e and f; Supplementary Tables 7 and 8).

\section{Standardized effect of disease activity on lipid profile}

Finally, comparing standardized coefficients, Fig. 5 shows that disease activity induced a dose-dependent effect on HDL-C (decreasing its levels) and oxLDL-C 


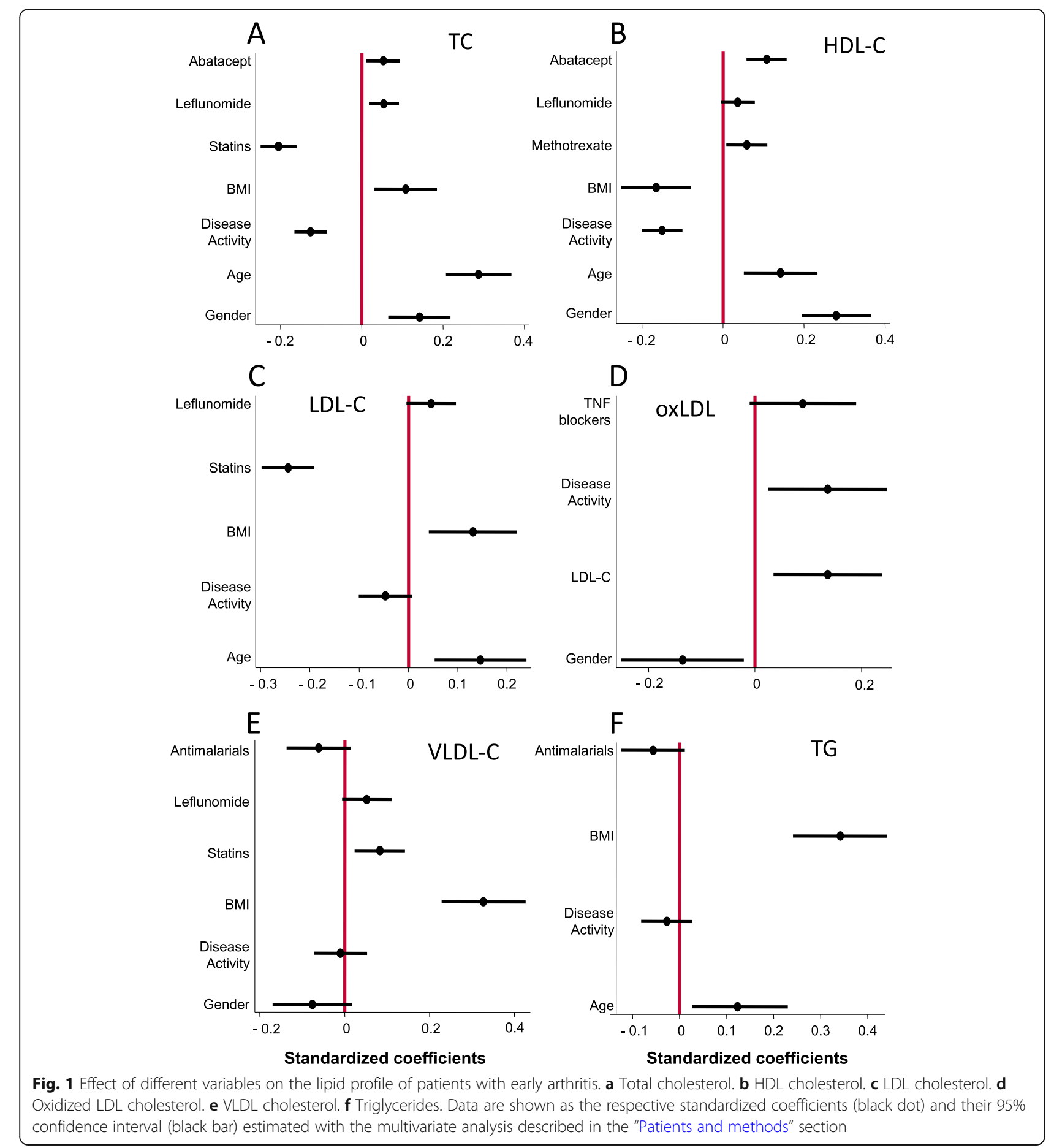

(increasing its levels). However, a mild effect on total LDL-C was observed; therefore, the decrease in TC when patients are active mainly relies on the HDL-C fraction (Fig. 5).

On the other hand, we were interested in which component of the composite indexes had a greater influence on the changes in lipids. CRP, followed by the swollen joint count, had the highest effect on lipids, especially on
LDL-C, being the effect of tender joints and global disease assessment by the patient which is the lowest (Supplementary Figure 2).

\section{Discussion}

The findings described in this study suggest that highdisease activity in patients with EA induces a transformation of their lipid profile into a pro-atherogenic one by 


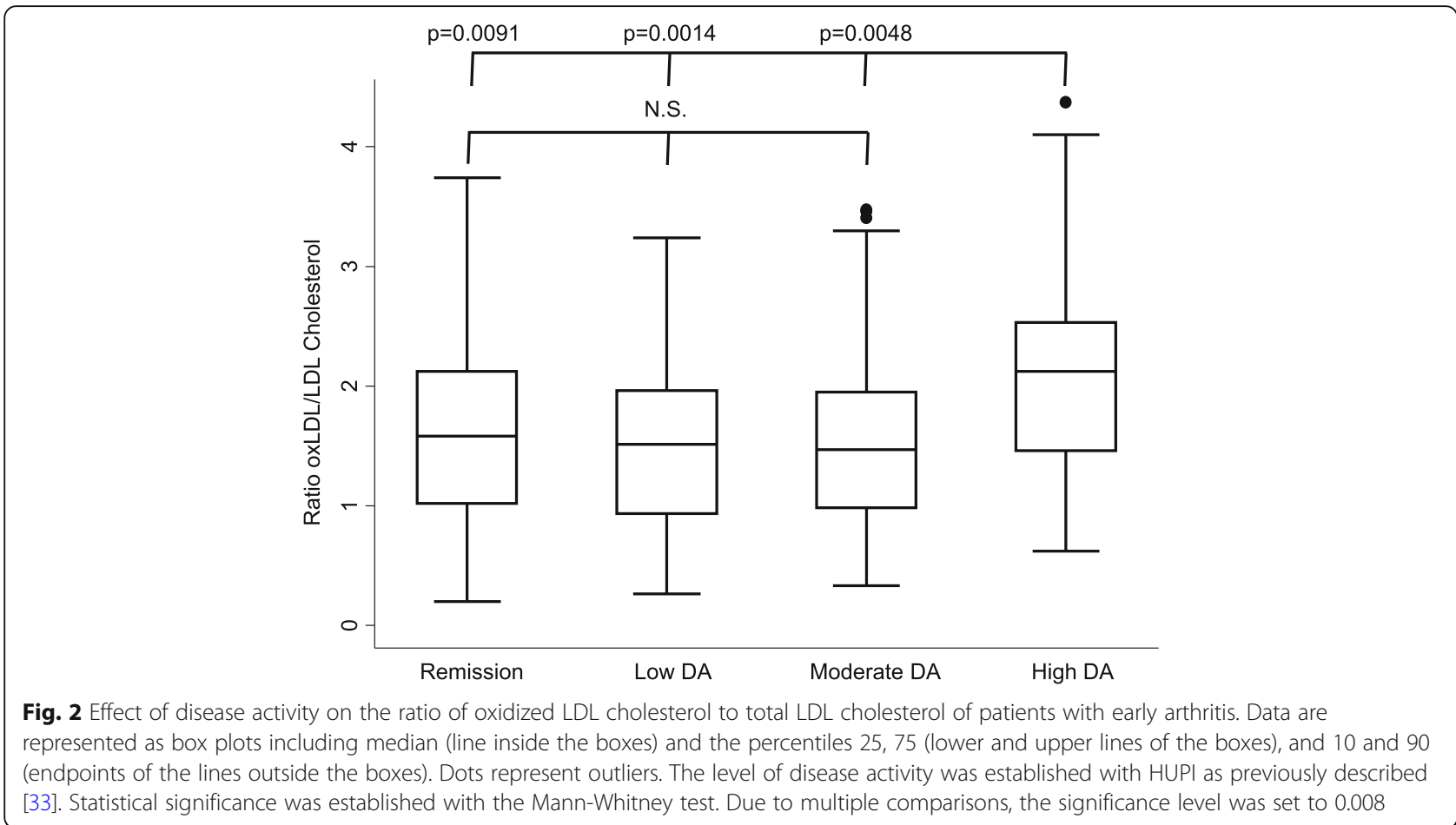

inducing a decrease in HDL-C levels and promoting LDL oxidation. In addition, the longitudinal design of our study and the availability of many variables that may affect cholesterol levels have allowed us to determine that the effect of disease activity on the levels of LDL-C fraction is limited and probably not so relevant. Interestingly, our data show that those patients with low LDL-C suffer a proportionally higher oxidation of this molecule, a finding that may explain the lipid paradox theory.
With regard to the effect of disease activity on lowering HDL-C levels, our data are in accordance with information reported previously [38-40]. Disease activity had a similar effect to other variables, such as gender and BMI, reported to affect HDL-C levels in the general population. However, disease activity has an additional effect on HDL-C since different studies suggest that an inflammatory state not only decreases the levels of HDL-C but also has an influence in its atheroprotective

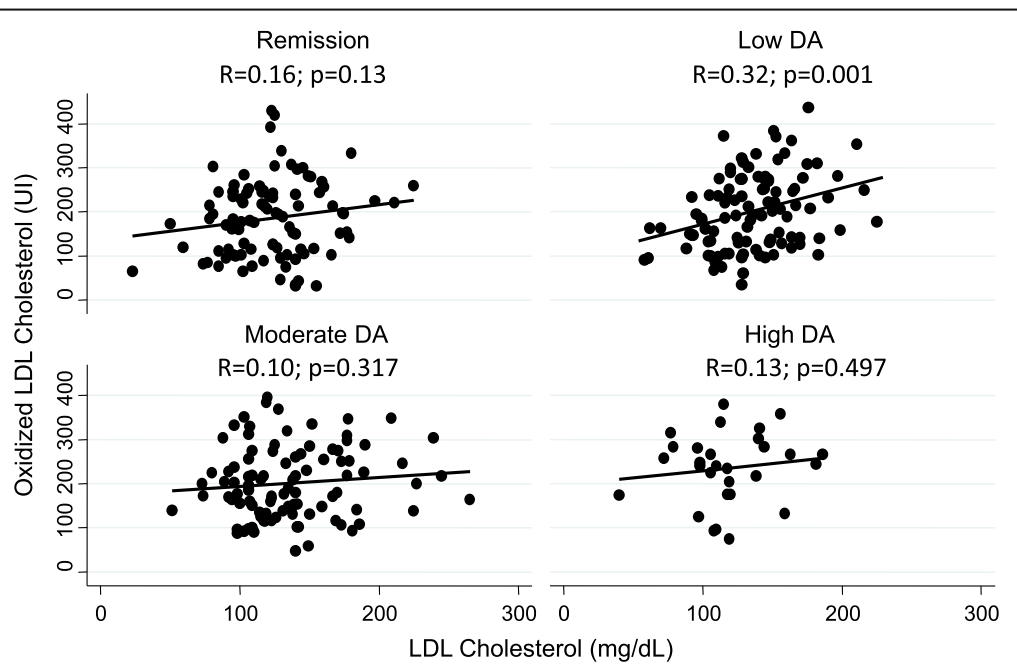

Fig. 3 Correlation between oxidized LDL cholesterol and total LDL cholesterol according to the level of disease activity in patients with early arthritis. Data are shown as dot plots of the values in the visits in which the patients were in remission (upper left panel), low (upper right panel), moderate (lower left panel), or high-disease activity (DA) established with HUPI as previously described [33]. Black lines represent the respective linear regressions estimated through the twoway Ifit command of Stata 12.1. $R$ and $p$ values were obtained with the Pearson's test 


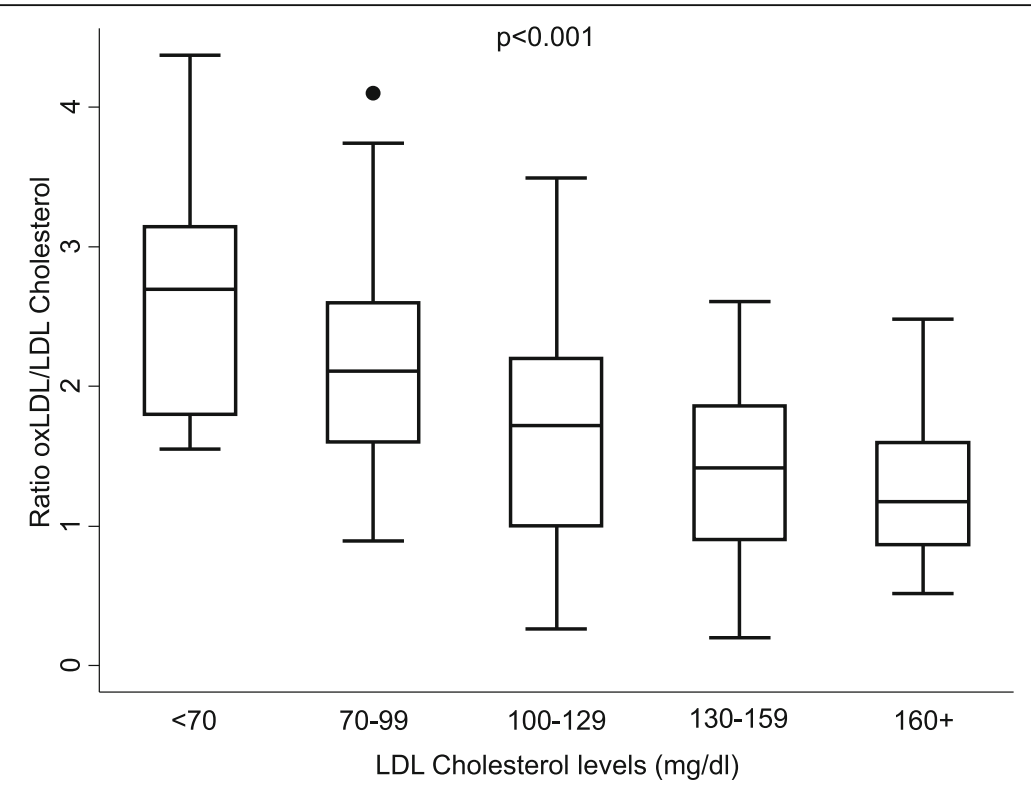

Fig. 4 Ratio of oxidized LDL cholesterol to LDL cholesterol in patients with early arthritis classified in different strata according to their $L D L$ cholesterol level. Data are represented as box plots including median (line inside the boxes) and the percentiles 25, 75 (lower and upper lines of the boxes), and 10 and 90 (endpoints of the lines outside the boxes). Dots represent outliers. Strata of LDL cholesterol levels were defined as described by Giles et al. [23]. Statistical significance was established using Cuzick's non-parametric trend test, and the significance level was set to 0.05

capacity $[39,41,42]$. Therefore, the usual HDL functions are abolished transforming HDL-C into a proatherogenic factor $[43,44]$. Regarding the mechanisms underlying these changes in the HDL-C fraction, it has been proposed that myeloperoxidase (MPO) released by phagocytes during the inflammatory process can induce the production of substances driving changes in the HDL-C fraction, especially oxidation of lipids and apoprotein A1 (apoA1) [45].

Our data also shed light into the paradoxical finding of low LDL-C levels in RA together with a high prevalence of $\mathrm{CV}$ disease associated with this disorder. Our

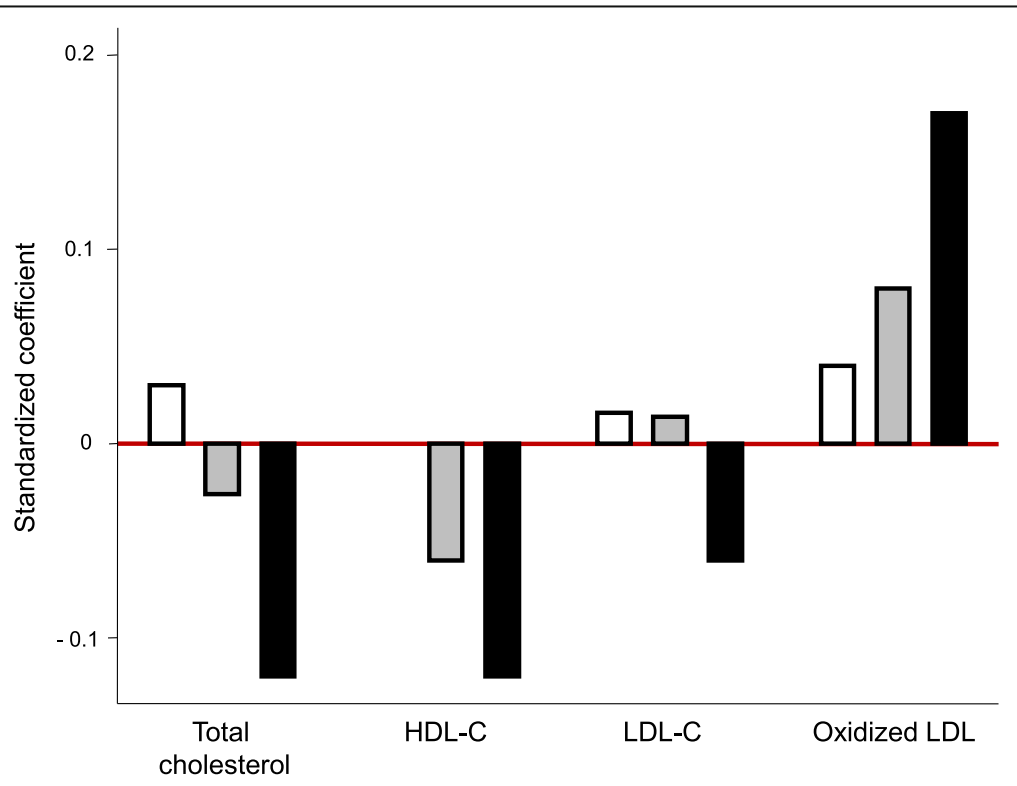

Fig. 5 Comparative effect of disease activity on the lipid profile of patients with early arthritis. Data are shown as the standardized coefficients of low-disease activity (DA; white bar), moderate DA (gray bar), and high-disease activity (black bar) from the multivariate analysis described in the "Patients and methods" section. Remission was the reference category of the disease activity variable 
multivariate analysis let us unravel that disease activity has an effect on total LDL-C levels in patients with EA. Among the different components included in disease activity indexes, CRP displayed the highest effect in lowering TC and LDL-C. Thus, our results point to IL-6 as a responsible for this finding, since it has been described that this cytokine increases the LDL receptor on hepatocytes and LDL-C catabolism, that improve after blockade of IL-6 signaling [46-48]. However, the inflammatory status, especially in patients with high-disease activity, has the most potent association with LDL oxidation compared to its effect in other lipid fractions. This observation is in accordance with previous reports [49]. In addition, the patients with lower levels of LDL-C were those with proportionally higher levels of oxLDL-C, which could explain why these patients show higher levels of atherosclerosis [23]. Furthermore, it has been described as an increase in anti-oxLDL antibody levels when RA patients are active which improves after controlling the disease activity, suggesting that oxLDL-C may act as an autoantigen [50].

Regarding the mechanisms underlying LDL oxidation, it is likely that two mechanisms may contribute: as described for HDL oxidation, the degranulation of phagocytes increases the level of oxygen radicals and of MPO activity, along with a reduction of Paraoxonase 1 (PON1) enzymatic function in HDL-C [43, 51]. PON1, an HDL-associated hydrolytic enzyme with a wide range of substrates, is responsible for most of the antioxidant properties of HDL and has a high capability of protecting against lipid oxidation in inflammation as well as in normal physiologic situations [52-54]. In addition, PON1 has a protective role in coronary artery disease and ischemic stroke [55]. Since several studies indicate that PON1 activity is reduced in inflammatory chronic diseases such as RA [56, 57], it is likely that a decrease in PON1 function can explain the atherogenic lipid profile observed when our patients display a high-disease activity and therefore the increased risk for CVE [58].

The longitudinal design of our study allowed us to clarify whether the effect of different drugs on lipid levels is related to the improvement of disease activity or there is a specific effect of these drugs. This question was raised for different drugs in several clinical trials $[39,59,60]$. Our data suggest that methotrexate, abatacept, and probably leflunomide may exert a beneficial effect upon HDL-C levels that would be independent of the improvement of disease activity, although the size of the effect of these treatments seems to be low.

Our study has some limitations. First, the serum lipid profile of patients included in this study was not available in all the visits of all patients. This is a common drawback in observational retrospective studies, but we think that it could be compensated by the high number of patients and visits carried out, which allowed us to implement longitudinal multivariate analysis nested by the patient and visit with more than 950 visits for the different fractions and more than 1400 visits for TC. The only exception was oxLDL-C analysis, which included 259 visits in 157 patients. This was the consequence of the second limitation of our study, measuring oxLDL-C levels in frozen serum samples. Most kits for measurement of oxLDL, including that from Mercodia ${ }^{\circ}$ used in this study, recommend using fresh serum samples. However, due to the retrospective nature of our study, we had to use frozen serum samples limiting the number of samples as it was described in the "Patients and methods" section and requiring adjusting the analysis for the time of frozen storage. Nevertheless, despite this limitation, we think that the analysis of oxLDL-C in our study provides interesting information.

Another potential limitation refers to the analysis of the effect of biologic therapies on the lipid profile. Since we studied mainly the first 5 years of follow-up of patients with EA, few visits included treatment with such drugs. The best represented was the TNF inhibitors group (Supplementary Table 1), but the information provided in this study on the effect of abatacept on HDL-C levels relies on information from few visits and it has to be confirmed in a specific study. However, it fits well with a recent study suggesting that abatacept reduces CV risk by $20 \%$ more than TNF inhibitors [61].

\section{Conclusions}

Overall, our data suggest that mainly patients that remain with moderate and high-disease activity suffer an additional risk of $\mathrm{CV}$ disease due to RA, since only these patients show relevant changes in the levels of HDL-C fraction and oxLDL-C. In addition, the changes in oxLDL-C are especially relevant in patients with low LDL-C. These findings are in keeping with descriptions showing a decreased incidence of $\mathrm{CV}$ disease in patients treated either with methotrexate or biologic agents [6264], since an increasing number of patients reach lowdisease activity and remission at present [65]. Moreover, our findings can also explain why a beneficial effect preventing cardiovascular events has not been observed with methotrexate in the general population [66] or with atorvastatin in non-selected RA patients [67].

\section{Supplementary information}

Supplementary information accompanies this paper at https://doi.org/10. 1186/s13075-020-02307-8.

Additional file 1: Supplementary Figure 1. Effect of time of frozen serum storage on the measurement of oxidized low density lipoproteins from patients with early arthritis. Data are shown as the individual values of 104 serum samples with a range of frozen storage from 6 to 40 
months (black dots) and the linear regression (black line) estimated through the twoway Ifit command of Stata 12.1.

Additional file 2: Supplementary Figure 2. Comparative effect of the different components of disease activity indexes on the total cholesterol levels. A) Total cholesterol. B) LDL cholesterol. C) HDL cholesterol. Data are shown as the standardized coefficients (black dots) and their respective 95\% confidence intervals (black lines) from the multivariate analysis described in Methods in which the variable disease activity was substituted by the different components included in the disease activity indexes: global disease assessment by patient (GDA Pat), tender joint count (TJC), swollen joint count (SJC) or C-reactive protein (CRP).

Additional file 3: Supplementary Table 1. Treatment prescribed to PEARL patients along the follow-up. Supplementary Table 2. Sensitivity analysis of variables that have influence on lipid profile only including patients that did not take statins. Supplementary Table 3. Variables that have influence on lipid profile, including disease activity estimated by CRP-DAS28. Supplementary Table 4. Variables that have influence on lipid profile, including disease activity, estimated with ESR-DAS28. Supplementary Table 5. Variables that have influence on lipid profile, including disease activity, estimated with SDAl. Supplementary Table 6. Variables that have influence on lipid profile, including disease activity, estimated with CDAI. Supplementary Table 7. Variables that have influence on VLDL Cholesterol levels. Supplementary Table 8. Variables that have influence on triglyceride levels.

Additional file 4. Raw data used for this work (in Stata format).

\section{Abbreviations}

ACPA: Anti-citrullinated protein antibodies; ACR: American College of Rheumatology; ApoA1: Apoprotein A1; $\beta$ coeff:: Beta coefficient; BMI: Body mass index; CV: Cardiovascular; CVE: Cardiovascular event; CDAl: Clinical Disease Activity Index; CRP: C-reactive protein; DAS28: Disease Activity Score (28 joints count); EA: Early arthritis; ESR: Erythrocyte sedimentation rate; HAQ: Health Assessment Questionnaire; HDL: High-density lipoproteins; HUPI: Hospital Universitario La Princesa Index; IQR: Interquartile range; LDL: Low-density lipoproteins; MTX: Methotrexate; MPO: Myeloperoxidase; N: Number; N: No; n.i.: Not included; oxLDL-C: Oxidized LDL cholesterol; p: $p$ value; PEARL: Princesa Early Arthritis Register Longitudinal;

PON1: Paraoxonase 1; RF: Rheumatoid factor; Ref.: Reference variable; SD: Standard deviation; SDAI: Simplified Disease Activity Index; s.e.: Standard error; sqrt: Square root; TC: Total cholesterol; TG: Triglycerides; TNF: Tumor necrosis factor; TNFi: TNF inhibitors; UA: Undifferentiated arthritis; VLDL: Very low-density lipoproteins; wk: Week; Y: Yes

\section{Acknowledgements}

The authors thank to Manuel Gómez-Gutiérrez, from the Methodology Unit, Hospital de La Princesa, Madrid, for his technical opinions and writing assistance. We want to particularly acknowledge the donors and the Biobank Biobanco Hospital Universitario de La Princesa (ISCIII B.0000763) for their collaboration.

\section{Authors' contributions}

IG-A, LA, MAGG, and SC contributed to the conception and/or design of the work. AMO, SP, AMF-O, ET, and IG-A contributed to acquisition of data. IG-A analyzed the data. IG-A, AMF-O, MAGG, and SC contributed to the interpretation of data. AMF-O drafted the manuscript. All other co-authors substantively revised it. All the authors approved the submitted version, agreed to be personally accountable for their own contributions and to ensure the accuracy or integrity of any part of the work.

\section{Funding}

Our manuscript was supported by grants RD16/0011/0012, RD16/0011/0009, RD16/0011/0004, PI05/2044, and PI18/0371 from the Ministerio de Economía y Competitividad (Instituto de Salud Carlos III) and co-funded by Fondo Europeo de Desarrollo Regional (FEDER).

\section{Availability of data and materials}

All data generated or analyzed during this study are included in the Supplementary File: raw_data.dta If needed, additional information could be available from the corresponding author on reasonable request.

\section{Ethics approval and consent to participate}

PEARL study is conducted according to the principles expressed in the Helsinki Declaration of 1983, and it was approved by the Research Ethics Committee of Hospital Universitario La Princesa (PI-518; March 28th, 2011). All patients included signed a written consent at study entry, and samples and data from patients included in this study were provided by the Biobank Biobanco Hospital Universitario de La Princesa (ISCIII B.0000763) and they were processed following standard operating procedures with the appropriate approval of the Ethics and Scientific Committees.

\section{Consent for publication}

Not applicable

\section{Competing interests}

AF-O, AMO, SP, ET, LA, and MAGG declare that they have no competing interests.

SC: reports personal fees from Abbvie, MSD, Lilly, Pfizer, Roche, Sanofi, Stada, UCB; nonfinancial support from Abbvie, BMS, Gebro, Lilly, MSD, Menarini, Novartis, Pfizer, Roche, UCB; and Academic help as Assistant professor of the Universidad Autonoma Madrid (UAM), for the course 2019-2020, from ROCHE-UAM.

IG-A: reports grants from Instituto de Salud Carlos III, during the course of the study; personal fees from Lilly and Sanofi; personal fees and non-financial support from BMS; personal fees and non-financial support from Abbvie; personal fees and non-financial support from Roche Laboratories; and nonfinancial support from MSD, Pfizer and Novartis, not related to the submitted work.

\section{Author details}

${ }^{1}$ Rheumatology Unit, Hospital General de Almansa, Albacete, Spain. ${ }^{2}$ Rheumatology Division, Hospital Universitario La Princesa, IIS-IP, Diego de León 62, 28006 Madrid, Spain. ${ }^{3}$ Rheumatology Division, Hospital Universitario Fundación Jiménez Díaz, Madrid, Spain. ${ }^{4}$ Rheumatology Division, Hospital Clínico San Carlos, IdISSC, Madrid, Spain. ${ }^{5}$ Rheumatology Division, Hospital Universitario Marqués de Valdecilla, IDIVAL, University of Cantabria, Santander, Spain. ${ }^{6}$ Cátedra UAM-Roche, EPID-Future, Universidad Autónoma Madrid, Madrid, Spain.

Received: 18 March 2020 Accepted: 31 August 2020

Published online: 11 September 2020

\section{References}

1. Gonzalez-Gay MA, Gonzalez-Juanatey C, Martin J. Rheumatoid arthritis: a disease associated with accelerated atherogenesis. Semin Arthritis Rheum. 2005;35(1):8-17.

2. Schieir O, Tosevski C, Glazier RH, Hogg-Johnson S, Badley EM. Incident myocardial infarction associated with major types of arthritis in the general population: a systematic review and meta-analysis. Ann Rheum Dis. 2017; 76(8):1396-404

3. Lopez-Mejias R, Castaneda S, Gonzalez-Juanatey C, Corrales A, Ferraz-Amaro I, Genre F, Remuzgo-Martinez S, Rodriguez-Rodriguez L, Blanco R, Llorca J, et al. Cardiovascular risk assessment in patients with rheumatoid arthritis: the relevance of clinical, genetic and serological markers. Autoimmun Rev. 2016;15(11):1013-30.

4. Skeoch S, Bruce IN. Atherosclerosis in rheumatoid arthritis: is it all about inflammation? Nat Rev Rheumatol. 2015;11(7):390-400.

5. Castaneda S, Nurmohamed MT, Gonzalez-Gay MA. Cardiovascular disease in inflammatory rheumatic diseases. Best Pract Res Clin Rheumatol. 2016;30(5): 851-69.

6. Gomez-Vaquero C, Corrales A, Zacarias A, Rueda-Gotor J, Blanco R, Gonzalez-Juanatey C, Llorca J, Gonzalez-Gay MA. SCORE and REGICOR function charts underestimate the cardiovascular risk in Spanish patients with rheumatoid arthritis. Arthritis Res Ther. 2013;15(4):R91.

7. Arts EE, Popa C, Den Broeder AA, Semb AG, Toms T, Kitas GD, van Riel PL, Fransen J. Performance of four current risk algorithms in predicting cardiovascular events in patients with early rheumatoid arthritis. Ann Rheum Dis. 2015;74(4):668-74.

8. Arts EE, Popa CD, Den Broeder AA, Donders R, Sandoo A, Toms T, Rollefstad S, Ikdahl E, Semb AG, Kitas GD, et al. Prediction of cardiovascular risk in rheumatoid arthritis: performance of original and adapted SCORE algorithms. Ann Rheum Dis. 2016;75(4):674-80. 
9. Semb AG, Ikdahl E, Hisdal J, Olsen IC, Rollefstad S. Exploring cardiovascular disease risk evaluation in patients with inflammatory joint diseases. Int J Cardiol. 2016;223:331-6.

10. Corrales A, Parra JA, Gonzalez-Juanatey C, Rueda-Gotor J, Blanco R, Llorca J, Gonzalez-Gay MA. Cardiovascular risk stratification in rheumatic diseases: carotid ultrasound is more sensitive than Coronary Artery Calcification Score to detect subclinical atherosclerosis in patients with rheumatoid arthritis. Ann Rheum Dis. 2013;72(11):1764-70.

11. Rodriguez-Rodriguez L, Lopez-Mejias R, Fernandez-Gutierrez B, Balsa A, Gonzalez-Gay MA, Martin J. Rheumatoid arthritis: genetic variants as biomarkers of cardiovascular disease. Curr Pharm Des. 2015;21 (2):182-201.

12. Boers M, Nurmohamed MT, Doelman CJ, Lard LR, Verhoeven AC, Voskuyl AE, Huizinga TW, van de Stadt RJ, Dijkmans BA, van der Linden S. Influence of glucocorticoids and disease activity on total and high density lipoprotein cholesterol in patients with rheumatoid arthritis. Ann Rheum Dis. 2003;62(9): $842-5$.

13. Charles-Schoeman C, Wang X, Lee YY, Shahbazian A, Navarro-Millan I, Yang S, Chen L, Cofield SS, Moreland LW, O'Dell J, et al. Association of riple therapy with improvement in cholesterol profiles over two-year followup in the treatment of early aggressive rheumatoid arthritis trial. Arthritis Rheumatol. 2016;68(3):577-86.

14. Charles-Schoeman C, Yin Lee Y, Shahbazian A, Wang X, Elashoff D, Curtis JR, Navarro-Millan I, Yang S, Chen L, Cofield SS, et al. Improvement of highdensity lipoprotein function in patients with early rheumatoid arthritis treated with methotrexate monotherapy or combination therapies in a randomized controlled trial. Arthritis Rheumatol. 2017;69(1):46-57.

15. Choi HK, Seeger JD. Lipid profiles among US elderly with untreated rheumatoid arthritis--the Third National Health and Nutrition Examination Survey. J Rheumatol. 2005;32(12):2311-6.

16. Georgiadis AN, Papavasiliou EC, Lourida ES, Alamanos Y, Kostara C, Tselepis $A D$, Drosos AA. Atherogenic lipid profile is a feature characteristic of patients with early rheumatoid arthritis: effect of early treatment--a prospective, controlled study. Arthritis Res Ther. 2006;8(3):R82.

17. Jamnitski A, Visman IM, Peters MJ, Dijkmans BA, Voskuyl AE, Nurmohamed MT. Beneficial effect of 1-year etanercept treatment on the lipid profile in responding patients with rheumatoid arthritis: the ETRA study. Ann Rheum Dis. 2010;69(11):1929-33.

18. Navarro-Millan I, Charles-Schoeman C, Yang S, Bathon JM, Bridges SL Jr, Chen L, Cofield SS, Dell'ttalia LJ, Moreland LW, O'Dell JR, et al. Changes in lipoproteins associated with methotrexate or combination therapy in early rheumatoid arthritis: results from the treatment of early rheumatoid arthritis trial. Arthritis Rheum. 2013;65(6):1430-8.

19. Yoo WH. Dyslipoproteinemia in patients with active rheumatoid arthritis: effects of disease activity, sex, and menopausal status on lipid profiles. J Rheumatol. 2004;31(9):1746-53.

20. Perk J, De Backer G, Gohlke H, Graham I, Reiner Z, Verschuren M, Albus C, Benlian P, Boysen G, Cifkova R, et al. European Guidelines on cardiovascular disease prevention in clinical practice (version 2012). The Fifth Joint Task Force of the European Society of Cardiology and Other Societies on Cardiovascular Disease Prevention in Clinical Practice (constituted by representatives of nine societies and by invited experts). Eur Heart J. 2012; 33(13):1635-701

21. Gonzalez-Gay MA, Gonzalez-Juanatey C. Inflammation and lipid profile in rheumatoid arthritis: bridging an apparent paradox. Ann Rheum Dis. 2014; 73(7):1281-3.

22. Hollan I, Dessein PH, Ronda N, Wasko MC, Svenungsson E, Agewall S, Cohen-Tervaert JW, Maki-Petaja K, Grundtvig M, Karpouzas GA, et al. Prevention of cardiovascular disease in rheumatoid arthritis. Autoimmun Rev. 2015;14(10):952-69.

23. Giles JT, Wasko MCM, Chung CP, Szklo M, Blumenthal RS, Kao A, Bokhari S, Zartoshti A, Stein CM, Bathon JM. Exploring the lipid paradox theory in rheumatoid arthritis: associations of low circulating low-density lipoprotein concentration with subclinical coronary atherosclerosis. Arthritis Rheumatol. 2019;71(9):1426-36.

24. Munro R, Morrison E, McDonald AG, Hunter JA, Madhok R, Capell HA. Effect of disease modifying agents on the lipid profiles of patients with rheumatoid arthritis. Ann Rheum Dis. 1997;56(6):374-7.

25. Ormseth MJ, Yancey PG, Solus JF, Bridges SL Jr, Curtis JR, Linton MF, Fazio S, Davies SS, Roberts $L$ 2nd, Vickers KC, et al. Effect of drug therapy on net cholesterol efflux capacity of high-density lipoprotein-enriched serum in rheumatoid arthritis. Arthritis Rheumatol. 2016;68(9):2099-105.
26. Rantapaa-Dahlqvist S, Wallberg-Jonsson S, Dahlen G. Lipoprotein (a), lipids, and lipoproteins in patients with rheumatoid arthritis. Ann Rheum Dis. 1991; 50(6):366-8

27. Arnett FC, Edworthy SM, Bloch DA, McShane DJ, Fries JF, Cooper NS, Healey LA, Kaplan SR, Liang MH, Luthra HS, et al. The American Rheumatism Association 1987 revised criteria for the classification of rheumatoid arthritis. Arthritis Rheum. 1988;31(3):315-24.

28. Verpoort KN, van Dongen H, Allaart CF, Toes RE, Breedveld FC, Huizinga TW. Undifferentiated arthritis--disease course assessed in several inception cohorts. Clin Exp Rheumatol. 2004;22(5 Suppl 35):S12-7.

29. Gonzalez-Alvaro I, Ortiz AM, Alvaro-Gracia JM, Castaneda S, Diaz-Sanchez B, Carvajal I, Garcia-Vadillo JA, Humbria A, Lopez-Bote JP, Patino E, et al. Interleukin 15 levels in serum may predict a severe disease course in patients with early arthritis. PLoS One. 2011;6(12):e29492.

30. Prevoo ML, van't Hof MA, Kuper $H H$, van Leeuwen $M A$, van de Putte $L B$, van Riel PL. Modified disease activity scores that include twenty-eight-joint counts. Development and validation in a prospective longitudinal study of patients with rheumatoid arthritis. Arthritis Rheum. 1995;38(1):44-8.

31. Castrejon I, Ortiz AM, Toledano E, Castaneda S, Garcia-Vadillo A, Patino E, Gonzalez-Alvaro I. Estimated cutoff points for the 28-joint disease activity score based on C-reactive protein in a longitudinal register of early arthritis. J Rheumatol. 2010;37(7):1439-43.

32. Aletaha D, Smolen J. The Simplified Disease Activity Index (SDAl) and the Clinical Disease Activity Index (CDAl): a review of their usefulness and validity in rheumatoid arthritis. Clin Exp Rheumatol. 2005;23(5 Suppl 39): S100-8.

33. Gonzalez-Alvaro I, Castrejon I, Ortiz AM, Toledano E, Castaneda S, GarciaVadillo A, Carmona L. Cut-offs and response criteria for the Hospital Universitario La Princesa index (HUPI) and their comparison to widely-used indices of disease activity in rheumatoid arthritis. PLoS One. 2016;11(9): e0161727.

34. Esteve-Vives J, Batlle-Gualda E, Reig A. Spanish version of the Health Assessment Questionnaire: reliability, validity and transcultural equivalency. Grupo Para la Adaptacion del HAQ a la Poblacion Espanola. J Rheumatol. 1993;20(12):2116-22.

35. Friedewald WT, Levy RI, Fredrickson DS. Estimation of the concentration of low-density lipoprotein cholesterol in plasma, without use of the preparative ultracentrifuge. Clin Chem. 1972;18(6):499-502.

36. Warnick GR, Knopp RH, Fitzpatrick V, Branson L. Estimating low-density lipoprotein cholesterol by the Friedewald equation is adequate for classifying patients on the basis of nationally recommended cutpoints. Clin Chem. 1990;36(1):15-9.

37. Pan W. Akaike's information criterion in generalized estimating equations. Biometrics. 2001;57(1):120-5.

38. Kerekes G, Nurmohamed MT, Gonzalez-Gay MA, Seres I, Paragh G, Kardos Z, Barath Z, Tamasi L, Soltesz P, Szekanecz Z. Rheumatoid arthritis and metabolic syndrome. Nat Rev Rheumatol. 2014;10(11):691-6.

39. Robertson J, Peters MJ, McInnes IB, Sattar N. Changes in lipid levels with inflammation and therapy in RA: a maturing paradigm. Nat Rev Rheumatol. 2013;9(9):513-23.

40. Souto A, Salgado E, Maneiro JR, Mera A, Carmona L, Gomez-Reino JJ. Lipid profile changes in patients with chronic inflammatory arthritis treated with biologic agents and tofacitinib in randomized clinical trials: a systematic review and meta-analysis. Arthritis Rheumatol. 2015;67(1):117-27.

41. Gomez Rosso L, Lhomme M, Merono T, Sorroche P, Catoggio L, Soriano E, Saucedo C, Malah V, Dauteuille C, Boero L, et al. Altered lipidome and antioxidative activity of small, dense HDL in normolipidemic rheumatoid arthritis: relevance of inflammation. Atherosclerosis. 2014:237(2):652-60.

42. Kim JY, Lee EY, Park JK, Song YW, Kim JR, Cho KH. Patients with rheumatoid arthritis show altered lipoprotein profiles with dysfunctional high-density lipoproteins that can exacerbate inflammatory and atherogenic process. PLoS One. 2016;11(10):e0164564.

43. Navab M, Anantharamaiah GM, Reddy ST, Van Lenten BJ, Ansell BJ, Fogelman AM. Mechanisms of disease: proatherogenic HDL--an evolving field. Nat Clin Pract Endocrinol Metab. 2006;2(9):504-11.

44. Zheng L, Nukuna B, Brennan ML, Sun M, Goormastic M, Settle M, Schmitt D, Fu X, Thomson L, Fox PL, et al. Apolipoprotein A-l is a selective target for myeloperoxidase-catalyzed oxidation and functional impairment in subjects with cardiovascular disease. J Clin Invest. 2004;114(4):529-41.

45. Vivekanandan-Giri A, Slocum JL, Byun J, Tang C, Sands RL, Gillespie BW, Heinecke JW, Saran R, Kaplan MJ, Pennathur S. High density lipoprotein is 
targeted for oxidation by myeloperoxidase in rheumatoid arthritis. Ann Rheum Dis. 2013;72(10):1725-31.

46. Robertson J, Porter D, Sattar N, Packard CJ, Caslake M, McInnes I, McCarey D. Interleukin-6 blockade raises LDL via reduced catabolism rather than via increased synthesis: a cytokine-specific mechanism for cholesterol changes in rheumatoid arthritis. Ann Rheum Dis. 2017;76(11):1949-52.

47. Strang AC, Bisoendial RJ, Kootte RS, Schulte DM, Dallinga-Thie GM, Levels JH, Kok M, Vos K, Tas SW, Tietge UJ, et al. Pro-atherogenic lipid changes and decreased hepatic LDL receptor expression by tocilizumab in rheumatoid arthritis. Atherosclerosis. 2013;229(1):174-81.

48. Venetsanopoulou Al, Pelechas E, Voulgari PV, Drosos AA. The lipid paradox in rheumatoid arthritis: the dark horse of the augmented cardiovascular risk. Rheumatol Int. 2020;40(8):1181-91.

49. Kim SH, Lee CK, Lee EY, Park SY, Cho YS, Yoo B, Moon HB. Serum oxidized low-density lipoproteins in rheumatoid arthritis. Rheumatol Int. 2004;24(4): 230-3.

50. Lourida ES, Georgiadis AN, Papavasiliou EC, Papathanasiou Al, Drosos AA, Tselepis AD. Patients with early rheumatoid arthritis exhibit elevated autoantibody titers against mildly oxidized low-density lipoprotein and exhibit decreased activity of the lipoprotein-associated phospholipase A2. Arthritis Res Ther. 2007:9(1):R19.

51. Kattoor AJ, Pothineni NVK, Palagiri D, Mehta JL. Oxidative stress in atherosclerosis. Curr Atheroscler Rep. 2017;19(11):42.

52. Mackness Ml, Arrol S, Durrington PN. Paraoxonase prevents accumulation of lipoperoxides in low-density lipoprotein. FEBS Lett. 1991;286(1-2):152-4.

53. Mackness MI, Arrol S, Abbott C, Durrington PN. Protection of low-density lipoprotein against oxidative modification by high-density lipoprotein associated paraoxonase. Atherosclerosis. 1993;104(1-2):129-35.

54. Aviram M, Rosenblat M, Bisgaier CL, Newton RS, Primo-Parmo SL, La Du BN. Paraoxonase inhibits high-density lipoprotein oxidation and preserves its functions. A possible peroxidative role for paraoxonase. J Clin Invest. 1998; 101(8):1581-90.

55. Litvinov D, Mahini H, Garelnabi M. Antioxidant and anti-inflammatory role of paraoxonase 1: implication in arteriosclerosis diseases. N Am J Med Sci. 2012;4(11):523-32.

56. Tanimoto N, Kumon Y, Suehiro T, Ohkubo S, Ikeda Y, Nishiya K, Hashimoto K. Serum paraoxonase activity decreases in rheumatoid arthritis. Life Sci. 2003;72(25):2877-85

57. Rodriguez-Carrio J, Alperi-Lopez M, Lopez P, Lopez-Mejias R, Alonso-Castro S, Abal F, Ballina-Garcia FJ, Gonzalez-Gay MA, Suarez A. High triglycerides and low high-density lipoprotein cholesterol lipid profile in rheumatoid arthritis: a potential link among inflammation, oxidative status, and dysfunctional high-density lipoprotein. J Clin Lipidol. 2017;11(4):1043-54 e1042.

58. Charles-Schoeman C, Lee YY, Shahbazian A, Gorn AH, Fitzgerald J, Ranganath VK, Taylor M, Ragavendra N, McMahon M, Elashoff D, et al. Association of paraoxonase 1 gene polymorphism and enzyme activity with carotid plaque in rheumatoid arthritis. Arthritis Rheum. 2013;65(11):2765-72.

59. Raterman HG, Levels H, Voskuyl AE, Lems WF, Dijkmans BA, Nurmohamed MT. HDL protein composition alters from proatherogenic into less atherogenic and proinflammatory in rheumatoid arthritis patients responding to rituximab. Ann Rheum Dis. 2013;72(4):560-5.

60. Charles-Schoeman C, Gugiu GB, Ge H, Shahbazian A, Lee YY, Wang X, Furst $D E$, Ranganath VK, Maldonado M, Lee T, et al. Remodeling of the HDL proteome with treatment response to abatacept or adalimumab in the AMPLE trial of patients with rheumatoid arthritis. Atherosclerosis. 2018;275: $107-14$.

61. Jin Y, Kang EH, Brill G, Desai RJ, Kim SC. Cardiovascular (CV) risk after initiation of Abatacept versus TNF inhibitors in rheumatoid arthritis patients with and without baseline CV disease. J Rheumatol. 2018;45(9):1240-8.

62. Bili A, Tang X, Pranesh S, Bozaite R, Morris SJ, Antohe JL, Kirchner HL, Wasko MC. Tumor necrosis factor alpha inhibitor use and decreased risk for incident coronary events in rheumatoid arthritis. Arthritis Care Res. 2014; 66(3):355-63.

63. Roubille C, Richer V, Starnino T, McCourt C, McFarlane A, Fleming P, Siu S, Kraft J, Lynde C, Pope J, et al. The effects of tumour necrosis factor inhibitors, methotrexate, non-steroidal anti-inflammatory drugs and corticosteroids on cardiovascular events in rheumatoid arthritis, psoriasis and psoriatic arthritis: a systematic review and meta-analysis. Ann Rheum Dis. 2015;74(3):480-9.
64. Widdifield J, Abrahamowicz M, Paterson JM, Huang A, Thorne JC, Pope JE, Kuriya B, Beauchamp ME, Bernatsky S. Associations between methotrexate use and the risk of cardiovascular events in patients with elderly-onset rheumatoid arthritis. J Rheumatol. 2019:46(5):467-74.

65. Toledano E, Ortiz AM, Ivorra-Cortes J, Montes N, Beltran A, RodriguezRodriguez L, Carmona L, Gonzalez-Alvaro I. Are rheumatologists adhering to the concepts window of opportunity and treat-to-target? Earlier and more intense disease-modifying anti-rheumatic drug treatment over time in patients with early arthritis in the PEARL study. Clin Exp Rheumatol. 2018; 36(3):382-8.

66. Ridker PM, Everett BM, Pradhan A, MacFadyen JG, Solomon DH, Zaharris E, Mam V, Hasan A, Rosenberg Y, Iturriaga E, et al. Low-dose methotrexate for the prevention of atherosclerotic events. N Engl J Med. 2019;380(8):752-62.

67. Kitas GD, Nightingale P, Armitage J, Sattar N, Belch JJF, Symmons DPM, Consortium TR. A multicenter, randomized, placebo-controlled trial of atorvastatin for the primary prevention of cardiovascular events in patients with rheumatoid arthritis. Arthritis Rheumatol. 2019;71(9):1437-49.

\section{Publisher's Note}

Springer Nature remains neutral with regard to jurisdictional claims in published maps and institutional affiliations.

Ready to submit your research? Choose BMC and benefit from:

- fast, convenient online submission

- thorough peer review by experienced researchers in your field

- rapid publication on acceptance

- support for research data, including large and complex data types

- gold Open Access which fosters wider collaboration and increased citations

- maximum visibility for your research: over $100 \mathrm{M}$ website views per year

At BMC, research is always in progress.

Learn more biomedcentral.com/submissions 